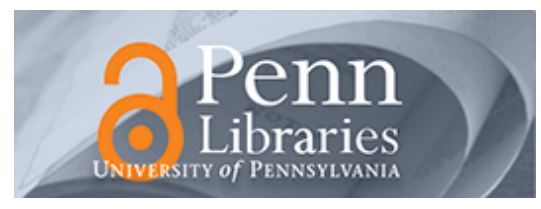

University of Pennsylvania

ScholarlyCommons

Operations, Information and Decisions Papers

Wharton Faculty Research

$3-2010$

\title{
I'll Have the Ice Cream Soon and the Vegetables Later: A Study of Online Grocery Purchases and Order Lead Time
}

Katherine L. Milkman

University of Pennsylvania

Todd Rogers

Max H. Bazerman

Follow this and additional works at: https://repository.upenn.edu/oid_papers

Part of the E-Commerce Commons, Marketing Commons, Operations and Supply Chain Management Commons, Other Social and Behavioral Sciences Commons, and the Social Psychology and Interaction Commons

\section{Recommended Citation}

Milkman, K. L., Rogers, T., \& Bazerman, M. H. (2010). I'll Have the Ice Cream Soon and the Vegetables Later: A Study of Online Grocery Purchases and Order Lead Time. Marketing Letters, 21 (1), 17-35. http://dx.doi.org/10.1007/s11002-009-9087-0

This paper is posted at ScholarlyCommons. https://repository.upenn.edu/oid_papers/79

For more information, please contact repository@pobox.upenn.edu. 


\title{
I'll Have the Ice Cream Soon and the Vegetables Later: A Study of Online Grocery Purchases and Order Lead Time
}

\begin{abstract}
How do decisions made for tomorrow or 2 days in the future differ from decisions made for several days in the future? We use data from an online grocer to address this question. In general, we find that as the delay between order completion and delivery increases, grocery customers spend less, order a higher percentage of "should" items (e.g., vegetables), and order a lower percentage of "want" items (e.g., ice cream), controlling for customer fixed effects. These field results replicate previous laboratory findings and are consistent with theories suggesting that people's should selves exert more influence over their choices the further in the future outcomes will be experienced. However, orders placed for delivery tomorrow versus 2 days in the future do not show this want/should pattern, and we discuss a potential explanation.
\end{abstract}

\section{Keywords}

lead time, intertemporal choice, want/should, E-commerce, intrapersonal conflict

\section{Disciplines}

E-Commerce | Marketing | Operations and Supply Chain Management | Other Social and Behavioral Sciences | Social Psychology and Interaction 
H A R VARD D B U S I N E S S S C H O O L

\section{I'll Have the Ice Cream Soon and the Vegetables Later: A Study of Online Grocery Purchases and Order Lead Time}

Katherine L. Milkman

Todd Rogers

Max H. Bazerman

\section{Working Paper}

07-078 


\title{
I'll Have the Ice Cream Soon and the Vegetables Later: A Study of Online Grocery Purchases and Order Lead Time
}

\author{
KATHERINE L. MILKMAN, TODD ROGERS, MAX H. BAZERMAN*
}

How do decisions made for tomorrow or two days in the future differ from decisions made for several days in the future? We use data from an online grocer to address this question. In general, we find that as the delay between order completion and delivery increases, grocery customers spend less, order a higher percentage of "should" items (e.g., vegetables), and order a lower percentage of "want" items (e.g., ice cream), controlling for customer fixed effects. These findings are all consistent with theories suggesting that people’s should selves exert more influence over their choices the further in the future outcomes will be experienced. However, orders placed for delivery tomorrow versus two days in the future do not show this want/should pattern, and we discuss a potential explanation.

*Author's note: Katherine L. Milkman, Ph.D. Candidate, Harvard Business School, Baker Library 444C, Soldiers Field Road, Boston, MA 02163, Ph. 617-496-0210, Fx. 617-496-4397, kmilkman@hbs.edu. Todd Rogers, Ph.D., Executive Director, Analyst Institute, Washington, DC. Max H. Bazerman, Professor, Harvard Business School, Baker Library 453, Soldiers Field Road, Boston, MA 02163.

Keywords: lead time, intertemporal choice, want/should, e-commerce, intrapersonal conflict 
As internet shopping becomes increasingly ubiquitous, a question of growing importance is whether and how demand for different types of products varies with order lead time. In traditional retailing situations, people consider their purchasing options and gain access to their selections in immediate succession. However, e-commerce retailers, which surpassed \$100 billion in sales for the first time in 2006 (comScore Press Release 2007), require customers to make choices about products one or more days before those customers will receive their selections. In addition, many e-commerce companies offer multiple shipping options, so customers can order products for delivery with different lead times. In this paper we investigate how a difference in the time delay separating an online order's completion and its delivery relates to the purchasing decisions made by consumers in the domain of grocery shopping.

Research on intertemporal choice suggests that when the time separating a purchasing decision from the receipt of a purchase is exogenously varied, this delay can significantly alter people's selections. Numerous laboratory studies and a burgeoning number of field studies have shown that people behave more impulsively - spending more, saving less, and more often choosing items they hedonically want to select over items they cognitively believe they should select - when outcomes are more immediate (for a review see Khan, Dhar and Wertenbroch 2004 or Milkman, Rogers and Bazerman 2008). The current research focuses on documenting the differences between choices made for the near future versus the more distant future in the field, while past field research has focused on examining the differences between choices made for now versus later.

In this paper, we use data provided by an online grocer to examine how the delay between an order's completion and its delivery relates to consumers' overall spending, purchases of should groceries (e.g., healthy foods like vegetables), and purchases of want groceries (e.g., unhealthy foods like ice cream). Our data set allows us to examine differences in people's choices over goods they will receive in the near future, beginning as early as tomorrow, versus the more distant future, controlling for customer fixed effects. We find that on average, the same 
consumers spend less and order a higher percentage of should goods and a lower percentage of want goods the further in advance of delivery they place a grocery order. These findings are consistent with hypotheses we develop based on multiple-selves theories of individual decision making (Shefrin and Thaler 1988; Bazerman et al. 1998; Read 2001) and with economic models of consumers as decreasingly impatient (see, for example, Loewenstein and Prelec 1992). However, it is important to note that another potential explanation for our findings is that the circumstances that lead people to plan further in advance are correlated with the circumstances that lead them to spend less and order relatively healthier foods. Our field data do not afford us the opportunity to disentangle which of these explanations is responsible for our results. However, the literature on intertemporal choice gave rise to our hypotheses, and we believe it offers a compelling explanation for our results, which have important implications for online retailers.

\section{RELEVANT PAST RESEARCH}

Past research on intrapersonal conflict, also known as the multiple selves phenomenon (Schelling 1984), has documented a tension between the behaviors people feel they should exhibit (e.g., saving more, going to the gym, starting a diet) and the behaviors they find themselves hedonically wanting to exhibit and often choosing to exhibit (e.g., spending more, watching television instead of going to the gym, and eating cake with lunch). Bazerman et al. (1998) describe this tension as stemming from two selves - a want self and a should self - which have competing preferences. Shefrin and Thaler (1988) also propose that people live in a state of internal conflict between multiple selves. They posit that people have two selves - a 'doer' self and a 'planner' self. The 'doer' self described by Shefrin and Thaler (1988) is consistent with the want self described by Bazerman et al. (1998), while Shefrin and Thaler's 'planner' self parallels Bazerman et al.’s should self.

The want self represents the desires people feel close to the time when a decision will take effect, while the should self represents the more deliberative feelings people have about what 
they ought to do given their long-term interests. The multiple selves framework predicts that in situations where outcomes will be more immediate, decision-makers will be more likely to make choices favoring their affective desires. This prediction suggests that spending decisions made for the nearer future will involve heightened overall spending as well as increased spending on goods that would be preferred by the want self, or "want goods", while spending decisions made for the more distant future will result in less spending overall as well as increased spending on goods preferred by the should self, or "should goods". ${ }^{1}$

Several experimental studies have approached the question of how people’s preferences differ when the outcomes of their decisions will be realized in the near future versus the more distant future. Benzion, Rapopport and Yagil (1989) conducted such a study, which employed a survey design that allowed the authors to estimate participants’ 6 month, 1 year, 2 year and 4 year discount rates over different hypothetical sums of money ( $\$ 40, \$ 200, \$ 1,000$ and $\$ 5,000)$. The authors found that participants' inferred discount rates decreased as the time they had to wait for a reward increased, meaning participants exhibited decreasing impatience. In another laboratory study, Zauberman and Lynch (2005) found that, on average, respondents reported being more likely to donate time to charity (a should behavior) in two weeks than tomorrow, a finding consistent with the idea that people are decreasingly impatient. In another series of laboratory studies, Rogers and Bazerman (2008) demonstrated that people are more likely to support should policies when those policies will be implemented in the distant future rather than in the near future.

The current paper provides a field examination of how longer delays between the time of a choice and the time of its realization relate to people's preferences for should versus want

\footnotetext{
${ }^{1}$ Economists have modeled this phenomenon by assuming individuals have a steep short-run discount rate and a relatively flat long-run discount rate, which leads them to overvalue present utility relative to future utility and thus to favor want options over should options at a higher rate the sooner their choices will take effect (see, for example, Loewenstein and Prelec 1992).
} 
options in the near future versus the more distant future using a large field data set from an online grocer. We test and find evidence supporting the following hypotheses:

H1: The further in advance of delivery a given customer completes an online grocery order, the less money she spends.

H2: The further in advance of delivery a given customer completes an online grocery order, the higher the proportion of should goods she purchases and the lower the proportion of want goods she purchases.

The rest of this paper is outlined as follows. We begin by describing the details of the data set we obtained from a large, online grocer and the methods we employ to classify the groceries in our data set on a spectrum from extreme should items to extreme want items. Next, we present the results of a series of panel regressions, which test the hypotheses articulated above. Finally, we conclude with a discussion of our findings and their implications.

\section{DATA}

\section{Overview of Data}

The online grocer we collaborated with on this study operates in North America and serves urban customers. Its customers place orders by browsing the products available on the company's website and adding items to an electronic grocery cart. Customers have the option to schedule a delivery during an available delivery slot for as early as tomorrow or for further in the future. During the period studied, the grocer charged a delivery fee for online orders. In addition, customers were required to spend a minimum dollar amount on each order. To preserve business confidentiality, company-specific information has been withheld from this document.

We obtained a novel panel data set from the aforementioned online grocery retailer containing information about the orders placed by all of the company's customers between January 1, 2005 and December 31, 2005. The online grocery company provided a record of each item in each order placed during the 12-month period in question, as well as the price each customer paid for each item, the date of each order, the date of each order's delivery, and the 
customer who placed each order. If a customer modified his or her order, we were told how many times order modifications were made, as well as the first and last dates when the customer modified his or her shopping basket. We operationalize order lead time in this paper as the time separating a customer's last visit to the grocer's website to change an order and the date when the customer's groceries were delivered. Note that online grocery customers could modify their selections after placing an initial order up until a cutoff time that allowed the online grocer time to shop, transport and deliver the customer's order. All customer accounts in our data set are labeled by anonymous, unique ID numbers. Our online grocery collaborator also provided us with category information about each item available for purchase through its website.

We restrict our analysis in this paper to customers who ordered groceries for delivery between one and five days in advance sometime between January 1, 2005 and December 31, 2005. We exclude all orders involving the redemption of a coupon because discount coupons have been shown to affect online grocery spending as well as the distribution of goods in a customer’s shopping basket (Milkman and Beshears 2008).

In total, between January 1, 2005 and December 31, 2005, tens of thousands of customers ordered groceries for delivery between one and five days in advance without redeeming a discount coupon. ${ }^{2}$ We eliminate each customer's first order of the year, ${ }^{3}$ spending outliers (top $1 \%$ ), and outliers in the number of visits made to the grocer's website during an order (top 1\%). This leaves us with over a million grocery orders in 2005 (customers in our analyses ordered an average of 5 to 10 times). The average dollar size of an order in this sample is $\$ 154.71$ and the average grocery order consists of 58 items. For additional summary statistics, see Table 1.

The majority of customers in our data set completed their grocery orders one day in advance of delivery. However, many customers completed orders between two and five days in advance of their scheduled delivery date (see Table 2). There is almost no seasonality in the rate

\footnotetext{
${ }^{2}$ Details about the number of unique customers, total number of grocery orders, and average number of orders per customer in our data set are not provided in order to preserve the anonymity of our data provider.

${ }^{3}$ This allows us to control for how much time has elapsed since a customer's last order in our analyses.
} 
at which customers' order lead times vary with the exception of slight volatility in January and

February and one unusual week in February. ${ }^{4}$ In all of our analyses of this data, we include week fixed effects, and we also re-run each analysis without January and February data to ensure that these two somewhat unusual months, when snowstorms may have affected both order lead times and the types of items customers purchased, are not driving our results.

\section{Classifying Groceries}

To classify the items in our grocery data set based on their position along the spectrum from should to want, we conducted an online survey. 154 people were paid to participate in this survey and answered questions about approximately 30 food categories from our database of groceries. Groceries in our data set have all been classified by our online grocer into one of 117 categories (e.g. Frozen Vegetables, Cream, Cookies, etc.). We randomly partitioned the grocery categories into four groups of approximately 30 categories each, and every survey participant was randomly assigned to answer questions about one of these four groups. Respondents were only asked about 30 grocery categories to reduce the likelihood of boredom and mechanical responses.

Our survey respondents were anonymous volunteers from all over the United States who signed up over the Internet to participate in online paid polls administered by the research lab of a large university. After being provided with concept definitions, ${ }^{5}$ respondents were asked to rate grocery categories along a 1 - 7 Likert scale anchored on not a "want” grocery category and a strong "want" grocery category, and a 1 - 7 Likert scale anchored on not a "should” grocery category and a strong "should" grocery category. Respondents saw the name of a grocery category and the names of its associated subcategories when completing our survey (e.g., Candy \& Gum: Candy Chocolate, Candy Non-Chocolate, Gum \& Mints), and the order in which they

\footnotetext{
${ }^{4}$ More details on the seasonality of order lead time are available upon request.

${ }^{5}$ Lengthy concept definitions were provided to participants and they were also quizzed on their understanding of these concepts. Full materials are available upon request. The final summary of a "want" grocery read: "The 'want' score is intended to reflect the extent to which someone's decision to consume this type of grocery would be indulgent and pleasure-based." The final summary of a "should" grocery read: "The 'should' score ought to reflect the extent to which someone's choice to consume the grocery would be made for virtuous, self-improving reasons, regardless of other potential factors.”
} 
were asked to rate grocery categories along should and want scales was randomized. No significant order effects were present in our survey data. ${ }^{6}$

We gave participants an incentive to provide accurate ratings of grocery categories by paying them for performance. For each grocery category a survey participant classified within one point of the average rating across respondents, her "accuracy score” was increased by one. The $20 \%$ of participants who received the highest accuracy scores were paid a bonus of $\$ 5$ on top of their \$5 participation fee.

To generate a single variable quantifying where on the spectrum from an extreme should to an extreme want each grocery category falls, we subtract each grocery category's want score from its should score. We average our raters' should minus want scores to create an overall should minus want index for each grocery category. If our survey ratings contain a meaningful signal, we should find that the should minus want scores assigned by different survey participants to the same grocery category are more tightly clustered than the should minus want scores assigned by different survey participants to different grocery categories. We run a one-way analysis of variance (ANOVA) to compare ratings variation between grocery categories to ratings variation within grocery categories (Shrout and Fleiss 1979). An intraclass correlation of 0.34 and an estimated reliability of a grocery category mean of 0.95 confirms that our survey averages are reliable - survey ratings vary significantly more between grocery categories than within grocery categories. For a catalog of the grocery categories in our sample and an ordered list of their associated average should minus want ratings, see Appendix.

In order to validate our should minus want metric, we examined the correlation between the average should minus want score for each of the grocery categories rated including foods and the average healthfulness rating (on a scale from $-5=$ very unhealthy to $+5=$ very healthy) given to the two most popular items in each of these grocery categories by a panel of 13 nutrition

\footnotetext{
${ }^{6}$ Wilks' lambdas from multivariate analysis of variances (MANOVAs) run to examine potential ordering effects were all insignificant at the $5 \%$ level.
} 
experts (see Martin, Beshears, Milkman, Bazerman and Sutherland 2008 for more on these expert ratings). A correlation of 0.49 (p-value $<0.0001$ ) indicates that our should minus want score is closely related to experts' perceptions of a food's healthfulness, increasing our confidence in this measure.

In addition to developing should minus want scores for each of the grocery categories in our data set, we created two other means of classifying should and want items so we would have multiple, imperfectly correlated measures of should and want groceries to use in our analyses. The grocery category designations used by the online grocery company allow us to classify a subset of foods as "fresh foods" (see Table 3). Conceptually, we argue that fresh foods items may be interpreted as a class of should groceries. In addition, we categorize a subset of groceries as “treats” following Heilman, Nakamoto and Rao’s (2002) definition of this class of goods. These authors created a list of treats based on the items that 57 grocery shoppers said they would buy if they "wanted to treat themselves or their families to something special” (Heilman et al. 2002, p. 246). Of the groceries that were listed, the $50 \%$ that were listed most often by these survey respondents were labeled "treats," as were goods found in the checkout aisle of a grocery store. We match grocery categories in our database to the groceries in the Heilman et al. "treats" list, as shown in Table 3, and we define goods that fall into these categories as "treats." Conceptually, this category may be interpreted as a class of extreme want groceries.

We constructed multiple outcome variables for our analyses using the grocery classifications discussed above. One of our outcome variables is conceptually designed to capture the overall makeup of a customer's grocery order. This variable is the average should minus want score of all of the groceries in a customer's basket. Two of our outcome variables are conceptually designed to capture groups of extreme should groceries: the percentage of an order’s dollar value composed of fresh foods and the percentage of an order's dollar value composed of groceries receiving one of the ten highest should minus want scores. Two of our outcome variables are conceptually designed to capture groups of extreme want groceries: the percentage 
of an order's dollar value composed of groceries receiving one of the ten lowest should minus want scores and the percentage of an order's dollar value composed of treats. Table 4 presents the correlations between these different outcome variables as well as summary statistics about dollar spending per order on each category of groceries.

\section{RESULTS}

We begin by evaluating the relationship between the time separating an order’s completion from its delivery and customer spending. Table 5 presents the results of ordinary least squares (OLS) regressions estimating the relationship between the amount a customer spends on groceries and how far in advance of delivery she completes her grocery order. In these regressions and in subsequent regressions, the explanatory variables include the number of days in advance of delivery a customer completed her order, the number of times the customer visited the online grocer's website in the course of placing an order, the number of days between the first and last visit the customer made to the grocer's website in the course of placing an order, the number of days since the customer last received a grocery delivery, a dummy indicating if 60 or more days have passed since the customer's last grocery order, the number of orders placed by the customer year to date, dummies for the day of the week when the order was placed, dummies for the day of the week when the order was delivered, dummies for each week in 2005, and customer fixed effects. Standard errors are clustered at the customer level.

By including customer fixed effects, we are able to identify off of within-customer variation in our analyses of the effects of lead time on consumer choice. In other words, the results of our regressions provide insights into how customers' orders differ when the delay between order and delivery varies, controlling for the average decisions made by a given customer.

Consistent with the hypothesis that people spend money more freely when they make decisions for the more immediate future, we find that holding all else constant, the dollar size of a grocery order decreases by approximately 2.0 percent for each additional day that separates a 
customer's last visit to the online grocer's website and the date when her groceries are delivered (see Table 5, Regression (2)). Regression (1) in Table 5 indicates that this effect corresponds to approximately $\$ 2.70$ less in spending on groceries per day of additional order lead time. It is important to note that although this result is consistent with our first hypothesis, which is based on the theory that people's should selves exert more influence over their decisions the further in the future their decisions will take effect, there are many plausible alternative explanations for the observed decrease in spending associated with orders placed for the more distant future. For example, this result may be driven by the fact that people know more about exactly what their needs will be when ordering groceries for the more immediate future and thus purchase more groceries the sooner their groceries will be delivered.

In the following analyses we investigate the impact of delivery lead time on the percentage of a customer's spending that is concentrated on different types of goods and the average should minus want score of goods in a customer's basket. By looking at the percentage composition and average should minus want score of groceries in customers’ baskets, we control for the overall decrease in spending across categories of goods that is associated with orders placed for the more distant future.

In the regressions that follow, rather than simply including a linear effect for the number of days in advance of delivery a customer places an order, we also include a dummy variable indicating whether an order was completed one day in advance of delivery. We include this dummy variable because exploratory data analyses revealed that this regression specification was most appropriate given the patterns in our data. In order to determine the appropriate specification for our regressions, we began by running each analysis with dummy variables indicating the number of days in advance of delivery an order had been completed. These regressions demonstrated a consistent pattern - a linear trend was apparent in the should and want contents of orders completed between two and five days in advance of delivery, and orders completed one day in advance of delivery did not follow this monotonic pattern. 
In Table 5, we present the results of a series of OLS regressions estimating the relationship between the percentage of a customer's grocery spending concentrated on different types of should and want groceries, the average should minus want score of items in a customer's basket, and how many days in advance of delivery a customer completes her order. The results presented in Table 5 indicate that for orders completed between two and five days in advance of delivery, the further in advance of delivery a customer completes an order, the relatively more should goods and fewer want goods she will purchase, consistent with the hypothesis that people are more likely to favor should options over want options the further in advance of consumption they make decisions. However, contrary to our prediction, orders completed one day in advance of delivery contain about the same percentage of should and want goods as orders completed two days in advance of delivery. This apparent nonlinearity in customers' patterns of choice is persistent across different measures of should and want goods, although the nonlinearity lies within one standard error of the linear trend detected across our analyses. We will discuss this unexpected pattern in our data in more detail and offer a potential explanation for it in the discussion section of this paper. The remainder of this section, however, will focus on our findings with respect to the differences between orders completed between two and five days in advance of delivery.

Regression (3) in Table 5 demonstrates the effect of an increase in the time between an order's completion and its delivery on the average should minus want score of a grocery basket. It shows that for orders placed between two and five days in advance of delivery, for each additional day in advance of delivery an order is completed, the average should minus want score of an entire grocery basket increases by 0.0053 (or approximately 0.008 standard deviations). Regressions (4) and (5) in Table 5 provide information about the change in the percentage of an order composed of should items that is associated with a change in how far in advance of delivery the order is completed. These regressions show that for orders placed between two and five days in advance of delivery, for each additional day in advance of delivery an order is completed, the 
percent of the order composed of fresh foods increases by 0.24 (or an average of $\$ 0.37$ ), and the percent composed of groceries with the 10 highest should minus want scores increases by 0.12 (or an average of \$0.19). Regressions (6) and (7) in Table 6 focus on the change in the percentage of an order composed of want items that is associated with a change in how far in advance of delivery an order is completed. They show that for orders placed between two and five days in advance of delivery, for each additional day in advance of delivery an order is completed, the percent of the order composed of groceries with the 10 lowest should minus want scores decreases by 0.06 (or an average of $\$ 0.09$ ). In addition, the percent of an order composed of treats decreases by 0.04 (or an average of \$0.07). Each of these results is consistent with our general prediction that people will have a stronger preference for should goods and a weaker preference for want goods the further in advance of consumption they make their grocery selections. Each of these regressions also contains a nonlinearity of the type described above, which we did not predict. ${ }^{7}$

To ensure that our results are not driven by any unusual events in January and February that may have caused more orders to be completed further in advance of delivery than usual (see Overview of Data), we re-run all of the above analyses without including orders placed in these months. The results of our regressions remain meaningfully and statistically unchanged when orders placed in these months are eliminated. We also re-run all of the above analyses excluding orders made by customers who did not place orders with each of the five possible lead times examined in this paper, and the magnitude of the effects we observe do not differ meaningfully with this restricted sample, although their statistical significance is weakened somewhat. These additional analyses are all available upon request.

\section{DISCUSSION}

\footnotetext{
${ }^{7}$ Regressions examining the percent spending on the five grocery categories receiving the highest and lowest should minus want scores reveal the same patterns and are available upon request. These results also hold if grocery categories containing alcohol and/or cigarettes are removed.
} 
The results presented above demonstrate systematic differences in the choices the same customers make when they complete grocery orders between two and five days in advance of delivery. First, we find that customers spend less the further in advance of delivery they complete an online grocery order. Second, we find that for orders placed between two and five days in advance of delivery, for each additional day in advance of delivery an order is completed, the percent of an order composed of want groceries decreases and the percent composed of should groceries increases.

In addition to providing evidence that is consistent with our hypotheses about the impact of order lead time on online purchasing decisions, the regression analyses discussed above also expose one unexpected but persistent feature of our data. The results of our analyses indicate that orders completed one day in advance of delivery include a slightly lower proportion of want goods and a slightly higher proportion of should goods than orders placed two days in advance of delivery (although the difference is never significant). This pattern in our data is not consistent with our hypotheses or with previously discussed trends in the composition of orders completed between two and five days in advance of delivery.

In order to gain an understanding of what might account for this unexpected pattern in consumers' behavior, we ran a survey with 230 participants. Our survey was designed to test the hypothesis that people are more likely to order groceries for specific, planned meals (as opposed to general pantry stocking) when ordering for tomorrow than for the more distant future and that groceries ordered for specific, planned meals are more likely to be should items and less likely to be want items than groceries ordered for general pantry stocking. In other words, we hypothesized that groceries ordered for tomorrow are construed more concretely than groceries ordered for the more distant future and that concrete construal would lead people to visualize more planned meals, thus leading them to prefer should items. This hypothesis is based on previous research on construal level theory suggesting that when making choices for the more 
distant future, people tend to focus on more abstract features of their options than when making choices for the more immediate future (Trope and Liberman 2003).

Survey respondents were randomly assigned to a condition in which they were instructed to imagine ordering groceries for tomorrow, two days in the future or five days in the future. Consistent with our hypothesis, participants in the "tomorrow" condition reported creating hypothetical lists that contained significantly more groceries intended for specific meals (t (227) $=-3.49, p=.001)$ and fewer groceries intended for pantry stocking $(\mathrm{t}(227)=-1.92, p=.056)$ than participants in the other two conditions. Respondents also reported that groceries ordered for specific meals are significantly more likely to be should foods (binomial test of proportions, $\mathrm{N}=$ $168, p=.053$ ) and less likely to be want foods (binomial test of proportions, $\mathrm{N}=182, p<.001$ ) than groceries ordered for general pantry stocking.

Although the survey results described above do not provide the only plausible explanation for the unexpected pattern in our field data, they offer one potential explanation. Together, our field data and survey data suggest that increasing the lead time between a grocery order's completion and its delivery may give rise to two separate psychological effects. First, we present evidence from our field data set that is consistent with past research showing that people generally behave more impulsively the sooner their decisions will take effect. However, the field data we examine suggests that this pattern is not apparent when orders placed one and two days in advance of delivery are compared with one another. Our survey data offers a potential explanation for this: people order groceries for delivery tomorrow with more specific purposes in mind than when they order groceries for delivery in the more distant future, and this leads them to order more should groceries and fewer want for tomorrow than for the more distant future. We propose that these two effects may combine to produce the purchasing patterns we observe.

It is important to note that while the findings presented in this paper are generally consistent with our hypotheses, we cannot determine whether they result from multiple selves conflict, a correlation between the situational factors that lead people to order further in advance 
and lead to less impulsive behavior, or some other phenomenon altogether. In spite of this, we believe the findings we present in this paper may have a number of potentially important implications. First, they may have implications for online and catalog retailers that offer a range of goods for sale and also offer different delivery options. Such companies might be able to improve their demand forecasting by taking into account the fact that their customers may be likely to spend more and to order a higher percentage of want goods and a lower percentage of should goods for delivery in the near future than in the more distant future. They might also be able to increase their customers' spending by persuading them to place orders for the more immediate future.

Our finding that people select healthier foods for themselves the further in the future their groceries will be delivered also has potential policy implications. Motivated by past research on intertemporal choice and intrapersonal conflict, Rogers and Bazerman (2008) conducted a series of studies demonstrating that people are more likely to select should policies (e.g., increased taxes on fossil fuels, increased charitable spending, etc.) when they will be implemented in the distant future rather than the near future. Offering people should choices that will take effect in the future is a strategy that they termed "future lock-in.” Our finding that people are more likely to buy a higher proportion of should items and a lower proportion of want items the further in advance of delivery they order groceries suggests that "future lock-in” might be more effective the further in advance of implementation people are asked to vote on should policies.

Finally, combining the specific domain in which our research was conducted with past work on future lock-in, our findings may have implications for nutrition policy. Our findings suggest that encouraging people to order their groceries up to five days in advance of consumption could influence the healthfulness of the foods people consume. ${ }^{8}$ Similarly, asking students in schools to select their lunches up to a week in advance could increase the

\footnotetext{
${ }^{8}$ Although it is possible that people only buy a healthier bundle of groceries when they order further in the future and do not actually eat healthier groceries, it seems likely that purchases are highly correlated with consumption.
} 
healthfulness of the foods they elect to eat. An attractive aspect of policies like these is that they preserve the decision-maker's choice set and autonomy by changing only the context in which decisions are made. By changing the decision context, policy-makers can increase the likelihood that people will make 'better’ choices without infringing upon their freedom (Sunstein and Thaler 2003).

\section{ACKNOWLEDGEMENTS}

The authors thank John Beshears, George Loewenstein, Kathleen McGinn, Nava Ashraf, and David Parkes, Carey Morewedge, Bill Simpson and Sarah Woolverton for their help with project.

\section{REFERENCES}

Bazerman, M. H., Tenbrunsel, A. E., \& Wade-Benzoni, K. (1998). Negotiating with yourself and losing: Making decisions with competing internal preferences. Academy of Management Review, 23(2), 225-241.

Benzion, U., Rapopport, A., \& Yagil, Y. (1989). Discount rates inferred from decisions: An experimental study. Management Science, 35(3), 270-284.

comScore Networks Reports Total Non-Travel E-Commerce Spending Reaches \$102 Billion in 2006; up 24 Percent Versus 2005. comScore Press Release. January 3, 2007. Accessed April 30, 2008: http://www.comscore.com/press/release.asp?press=1166.

Heilman, C. M., Nakamoto, K., \& Rao, A.G. (2002). Pleasant surprises: Consumer response to unexpected in-store coupons. Journal of Marketing Research, 39(2), 242-252.

Loewenstein, G.F. \& Prelec, D. (1992). Anomalies in intertemporal choice: Evidence and an Interpretation. Quarterly Journal of Economics, 107, 573-597.

Khan, U., Dhar, R. \& Wertenbroch, K. (2005). A behavioral decision theory perspective on hedonic and utilitarian choice. In S. Ratneshwar and D.G. Mick (Eds.), Inside Consumption: Frontiers of Research. 
on Consumer Motives, Goals, and Desires, (pp. 144 - 165). Routledge, London.Martin, J.M.,

Beshears, J., Milkman, K.L., Bazerman, M.H., \& Sutherland, L. (2008). Modeling expert opinions on food healthiness: A nutrition metric. HBS Working Paper 08-082.

Milkman, K.L., Rogers, T., \& Bazerman, M.H. (2008). Harnessing our inner angels and demons: What we have learned about want/should conflicts and how that knowledge can help us reduce short-sighted decision making. Perspectives on Psychological Science, 3, 324 - 338.

Milkman, K. L. \& Beshears, J. (2008). Mental accounting and small windfalls: Evidence from an online grocer. HBS Working Paper 08-024.

Read, D. (2001). Intrapersonal dilemmas. Human relations. 54(8), 1093 - 1117.

Rogers, T. \& Bazerman, M.H. (2008). Future lock-in: Future implementation increases selection of should choices. Organizational Behavior and Human Decision Processes. 106(1), 1 - 20.

Schelling, T.C. (1984), Choice and consequence: Perspectives of an errant economist. Cambridge, MA: Harvard University Press.

Shefrin, H. \& Thaler, R.H. (1988). The behavioral life-cycle hypothesis. Economic Inquiry. 26(4), $609-643$.

Shrout, P.E. \& Fleiss, J.L. (1979). Intraclass correlations: Uses in assessing rater reliability. Psychological Bulletin, 86(2), 420-428.

Sunstein, C.R. \& Thaler, R.H. (2003). Libertarian paternalism is not an oxymoron. University of Chicago Law Review, 70(Fall), 1159-99.

Trope, Y. \& Liberman, N. (2003). Temporal construal. Psychological Review, 110, 403-421.

Zauberman, G. \& Lynch, J.G. (2005). Resource Slack and Propensity to Discount Delayed Investments of Time versus Money. Journal of Experimental Psychology: General. 134 (1), 23-37.

TABLES

\begin{tabular}{lcc}
\hline \multicolumn{3}{c}{ Table 1. Summary Statistics } \\
\hline \multirow{3}{*}{ Spending } & \multicolumn{1}{c}{ Mean } & Standard Deviation \\
\cline { 2 - 3 }
\end{tabular}




\begin{tabular}{lcc} 
Number of Groceries & 58.38 & 25.95 \\
Number of Web Visits for Order & 3.27 & 2.59 \\
Days btw First and Last Web Visits for Order & 1.37 & 0.73 \\
Days Since Last Delivery & 21.84 & 29.48 \\
\hline
\end{tabular}

\begin{tabular}{lc}
\hline \multicolumn{3}{c}{ Table 2. Delivery Lead Time Summary Statistics } \\
\hline \% of Orders Completed 1 Day in Advance of Delivery & $74.40 \%$ \\
\% of Orders Completed 2 Days in Advance of Delivery & $18.17 \%$ \\
\% of Orders Completed 3 Days in Advance of Delivery & $4.76 \%$ \\
\% of Orders Completed 4 Days in Advance of Delivery & $1.85 \%$ \\
\% of Orders Completed 5 Days in Advance of Delivery & $0.82 \%$ \\
\hline
\end{tabular}

Summary statistics describing the percentage of orders completed varying numbers of days in advance of delivery, excluding each customer's first order of 2005.

\begin{tabular}{|c|c|c|}
\hline & \multicolumn{2}{|c|}{ Table 3. Classification of Groceries } \\
\hline \multirow[t]{2}{*}{ Fresh Foods } & \multicolumn{2}{|r|}{ Treats } \\
\hline & In Heilman et al. (2002) & Corresponding Groceries in Our Data \\
\hline PRODUCE-VEGETABLES & Ice Cream & ICE CREAM (Category) \\
\hline MEAT-FRESH & Bakery Goods & BAKERY-FRESH (Category) \\
\hline SEAFOOD-FRESH & Steak & ALL OTHER FRESH MEAT (Sub-category) \\
\hline PRODUCE-FRUITS & & MEAT (Sub-category) \\
\hline DELI-FRESH & Wine & WINE/WINE COOLERS (Sub-category) \\
\hline \multirow[t]{19}{*}{ BAKERY-FRESH } & Candy & CANDY \& GUM (Category) \\
\hline & Cheese & CHEESE (Category) \\
\hline & Cookies & COOKIES (Category) \\
\hline & Magazine & MAGS/NEWSPAPERS/BOOKS (Sub-category) \\
\hline & Chocolate & CANDY \& GUM (Category) \\
\hline & & HOT CHOCOLATE MIX (Sub-category) \\
\hline & Flowers & FLORAL (Category) \\
\hline & Cake & CAKE MIXES (Sub-category) \\
\hline & & CAKES (FRESH) (Sub-category) \\
\hline & Seafood & SEAFOOD-FRESH (Category) \\
\hline & & SEAFOOD-FROZEN (Category) \\
\hline & Baby Toy & NA \\
\hline & Chips & POTATO CHIPS (Sub-category) \\
\hline & & TORTILLA CHIPS (Sub-category) \\
\hline & & CORN CHIPS/SNACKS (Sub-category) \\
\hline & Cosmetics & COSMETICS (Category) \\
\hline & Movie Rental & MUSIC/MOVIES (Sub-category) \\
\hline & Pie & PIES (FRESH) (Sub-category) \\
\hline & Gum/Mints & CANDY \& GUM (Category) \\
\hline
\end{tabular}

Table 4. Correlations between Outcome Measures and Summaries of Spending on Each Category of Groceries

\begin{tabular}{lccccc}
\hline & Basket's & \multicolumn{2}{c}{$\%$ of Order's Dollar Value Composed of: } \\
\cline { 5 - 6 } & Avg. SMW & Fresh & 10 Highest & 10 Lowest & Treats \\
& Score & Foods & SMW Scores & SMW Scores & \\
\hline Fresh Foods & $0.3722^{* * *}$ & & & & \\
10 Highest SMW Scores & $0.5524^{* * *}$ & $0.1865^{* * *}$ & & & \\
10 Lowest SMW Scores & $-0.4551^{* * *}$ & $-0.1860^{* * *}$ & $-0.1510^{* * *}$ & & \\
Treats & $-0.3098^{* * *}$ & 0.0006 & $-0.1572^{* * *}$ & $0.5485^{* * *}$ & \\
\hline Average Spending/(Score) on Category & -0.0646 & $\$ 39.00$ & $\$ 21.84$ & $\$ 7.21$ & $\$ 14.91$ \\
Std of Spending/(Score) on Category & 0.6678 & $\$ 29.20$ & $\$ 16.36$ & $\$ 10.95$ & $\$ 14.28$ \\
\hline
\end{tabular}

$*, * *$, and $* * *$ denote significance at the 10 percent, 5 percent, and 1 percent levels, respectively. 
Table 5. The Effects of Order Lead Time on Spending and Purchases of Want and Should Groceries

\begin{tabular}{|c|c|c|c|c|c|c|c|}
\hline & \multirow[b]{2}{*}{$\begin{array}{c}\text { Spending } \\
\text { (1) }\end{array}$} & \multirow[b]{2}{*}{$\begin{array}{c}\text { Log(1+ } \\
\text { Spending) } \\
\text { (2) }\end{array}$} & \multirow{2}{*}{$\begin{array}{c}\text { Basket's } \\
\text { Average } \\
\text { SMW Score } \\
\text { (3) }\end{array}$} & \multicolumn{4}{|c|}{ \% of Order's Dollar Value Composed Of } \\
\hline & & & & $\begin{array}{c}\text { Fresh } \\
\text { Foods } \\
(4) \\
\end{array}$ & $\begin{array}{c}10 \text { Highest } \\
\text { SMW Scores } \\
(5)\end{array}$ & $\begin{array}{l}10 \text { Lowest } \\
\text { SMW Scores } \\
(6)\end{array}$ & $\begin{array}{c}\text { Treats } \\
\text { (7) }\end{array}$ \\
\hline One Day btw Order Completion and Delivery & & & $\begin{array}{l}0.0070 * * * \\
(0.0026)\end{array}$ & $\begin{array}{l}0.0028 * * * \\
(0.0005)\end{array}$ & $\begin{array}{l}0.0009 * * \\
(0.0004)\end{array}$ & $\begin{array}{l}-0.0010^{* * *} \\
(0.0002)\end{array}$ & $\begin{array}{l}-0.0005 \\
(0.0004)\end{array}$ \\
\hline Days btw Order Completion and Delivery & $\begin{array}{l}-2.6994 * * * \\
(0.0860)\end{array}$ & $\begin{array}{l}-0.0195^{* * *} \\
(0.0005)\end{array}$ & $\begin{array}{l}0.0053^{* * *} \\
(0.0019)\end{array}$ & $\begin{array}{l}0.0024^{* * *} \\
(0.0004)\end{array}$ & $\begin{array}{l}0.0012^{* * *} \\
(0.0003)\end{array}$ & $\begin{array}{l}-0.0006^{* * *} \\
(0.0002)\end{array}$ & $\begin{array}{l}-0.0004 * \\
(0.0003)\end{array}$ \\
\hline Number of Web Visits for Order & $\begin{array}{l}3.1705^{* * * *} \\
(0.0316)\end{array}$ & $\begin{array}{l}0.0209 * * * \\
(0.0002)\end{array}$ & $\begin{array}{l}-0.0023^{* * *} \\
(0.0003)\end{array}$ & $\begin{array}{l}-0.0015 * * * \\
(0.0001)\end{array}$ & $\begin{array}{l}-0.0002^{* * *} \\
(0.0000)\end{array}$ & $\begin{array}{l}0.0000 \\
(0.0000)\end{array}$ & $\begin{array}{l}0.0002^{* * *} \\
(0.0000)\end{array}$ \\
\hline Days btw First and Last Web Visits for Order & $\begin{array}{l}-0.1359 * * * \\
(0.0050)\end{array}$ & $\begin{array}{l}-0.0009 * * * \\
(0.0000)\end{array}$ & $\begin{array}{l}0.0000 \\
(0.0000)\end{array}$ & $\begin{array}{l}0.0001^{* * *} \\
(0.0000)\end{array}$ & $\begin{array}{l}0.0000 \\
(0.0000)\end{array}$ & $\begin{array}{l}0.0000 * * \\
(0.0000)\end{array}$ & $\begin{array}{l}0.0000 \\
(0.0000)\end{array}$ \\
\hline Days Since Last Delivery & $\begin{array}{l}0.2517 * * * \\
(0.0049)\end{array}$ & $\begin{array}{l}0.0016 * * * \\
(0.0000)\end{array}$ & $\begin{array}{l}0.0004^{* * *} \\
(0.0000)\end{array}$ & $\begin{array}{l}-0.0002^{* * *} \\
(0.0000)\end{array}$ & $\begin{array}{l}-0.0000^{* * *} \\
(0.0000)\end{array}$ & $\begin{array}{l}-0.0000^{* * *} \\
(0.0000)\end{array}$ & $\begin{array}{l}-0.0001^{* * * *} \\
(0.0000)\end{array}$ \\
\hline 60 or More Days Since Last Order & $\begin{array}{l}-11.8873 * * * \\
(0.4033)\end{array}$ & $\begin{array}{l}-0.0762^{* * *} \\
(0.0025)\end{array}$ & $\begin{array}{l}-0.0046 \\
(0.0030)\end{array}$ & $\begin{array}{l}0.0055^{* * *} \\
(0.0009)\end{array}$ & $\begin{array}{l}0.0021 * * * \\
(0.0006)\end{array}$ & $\begin{array}{l}0.0006 \\
(0.0004)\end{array}$ & $\begin{array}{l}0.0019 * * * \\
(0.0005)\end{array}$ \\
\hline Days Since First Order with Grocer x $1^{3}$ & $\begin{array}{l}70.7254^{* * *} \\
(0.0077)\end{array}$ & $\begin{array}{l}0.0005^{* * *} \\
(0.0000)\end{array}$ & $\begin{array}{l}-0.0416 \\
(0.0898)\end{array}$ & $\begin{array}{l}-0.0276 \\
(0.0187)\end{array}$ & $\begin{array}{l}-0.0151 \\
(0.0153)\end{array}$ & $\begin{array}{l}-0.0142 \\
(0.0106)\end{array}$ & $\begin{array}{l}-0.0299 * * \\
(0.0129)\end{array}$ \\
\hline Orders Year to Date & $\begin{array}{l}-0.0186 \\
(0.0201)\end{array}$ & $\begin{array}{l}-0.0002 \\
(0.0001)\end{array}$ & $\begin{array}{l}0.0007 * * * \\
(0.0002)\end{array}$ & $\begin{array}{l}-0.0001^{*} \\
(0.0000)\end{array}$ & $\begin{array}{l}0.0001^{* *} \\
(0.0000)\end{array}$ & $\begin{array}{l}0.0000 \\
(0.0000)\end{array}$ & $\begin{array}{l}-0.0001^{* *} \\
(0.0000)\end{array}$ \\
\hline Day of the Week Order Placed Fixed Effects & Yes & Yes & Yes & Yes & Yes & Yes & Yes \\
\hline Day of the Week Order Delivered Fixed Effects & Yes & Yes & Yes & Yes & Yes & Yes & Yes \\
\hline Week of the Year Fixed Effects & Yes & Yes & Yes & Yes & Yes & Yes & Yes \\
\hline Customer Fixed Effects & Yes & Yes & Yes & Yes & Yes & Yes & Yes \\
\hline Observations & 1 million+ & 1 million+ & 1 million+ & 1 million+ & 1 million+ & 1 million+ & 1 million+ \\
\hline $\begin{array}{l}\text { Customers } \\
\mathbf{R}^{2}\end{array}$ & $\begin{array}{l}100,000+ \\
0.6740\end{array}$ & $\begin{array}{l}100,000+ \\
0.6812\end{array}$ & $\begin{array}{l}100,000+ \\
0.6423\end{array}$ & $\begin{array}{l}100,000+ \\
0.6605\end{array}$ & $\begin{array}{l}100,000+ \\
0.5472\end{array}$ & $\begin{array}{l}100,000+ \\
0.5294\end{array}$ & $\begin{array}{l}100,000+ \\
0.4713\end{array}$ \\
\hline
\end{tabular}

Columns (1) and (2) report OLS coefficients from regressions of customer spending on a continuous variable indicating how far in advance of delivery an order was completed controlling for the other variables listed. Columns (3) through (7) report OLS coefficients from regressions of customer spending on categories of groceries on a dummy indicating whether an order was completed one day in advance of delivery and a continuous variable indicating how far in advance of delivery an order was completed, controlling for the other variables listed. Robust standard errors clustered at the customer level are in parentheses. *, **, and *** denote significance at the 10 percent, 5 percent, and 1 percent levels, respectively. 


\section{APPENDIX: AVERAGE SHOULD MINUS WANT SCORES FOR GROCERY CATEGORIES IN OUR DATA SET}

\begin{tabular}{|c|c|c|c|}
\hline Grocery Category & $\begin{array}{l}\text { Average Should } \\
\text { Minus Want Score }\end{array}$ & Grocery Category & $\begin{array}{l}\text { Average Should } \\
\text { Minus Want Score }\end{array}$ \\
\hline COOKIES & -5.098 & BREAKFAST & -0.481 \\
\hline WINE/WINE COOLERS & -4.976 & DRIED BREAD & -0.481 \\
\hline ICE CREAM & -4.976 & CONDIMENTS & -0.455 \\
\hline CANDY \& GUM & -4.420 & ICE & -0.444 \\
\hline CIGARS \& TOBACCO & -4.300 & BEVERAGES (RFG) & -0.364 \\
\hline MIXERS/BAR NEEDS & -4.140 & DIET CARE & -0.280 \\
\hline FROZEN PIZZA & -4.073 & FRUITS & -0.242 \\
\hline CIGARETTES & -4.000 & FILM/BATTERIES & -0.212 \\
\hline SPIRITS & -4.000 & BEVERAGES-TEA & -0.185 \\
\hline PREPARED COCKTAILS & -3.963 & AIR CARE & -0.182 \\
\hline COSMETICS & -3.951 & SEAFOOD-FROZEN & -0.148 \\
\hline FLORAL & -3.927 & SOAP & -0.061 \\
\hline BAKING MIXES & -3.659 & CHEESE & 0.024 \\
\hline FROZEN SNACKS/APPETIZERS & -3.600 & SEPTIC SYSTEM/SOFTNR SLT & 0.030 \\
\hline BEVERAGES-SODA & -3.600 & BABY HEALTH & 0.061 \\
\hline CREAM & -3.439 & DELI-FRESH & 0.061 \\
\hline FRZN POTATOES/ONION RINGS & -3.360 & AUTOMOTIVE & 0.122 \\
\hline TOYS/CARDS & -3.185 & MEAT-FROZEN & 0.140 \\
\hline BAKERY-COMMERCIAL & -3.049 & PESTICIDES/BUG REPELLNTS & 0.240 \\
\hline PARTY FAVORS/BALLOONS & -3.000 & HOUSEWARES & 0.364 \\
\hline BAKERY-FRESH & -2.951 & MEAT/SEAFOOD & 0.364 \\
\hline BAKING SUPPLIES/INGREDNTS & -2.902 & PASTA/GRAINS & 0.488 \\
\hline SPREADS & -2.854 & MEDICATIONS & 0.515 \\
\hline BEVERAGES-CREAMERS & -2.640 & OFFICE/SCHOOL SUPPLIES & 0.545 \\
\hline DIPS (RFG) & -2.481 & SKIN CARE & 0.556 \\
\hline SYRUP FLAVORNG (NO-BKFST) & -2.407 & BABY FOOD & 0.576 \\
\hline BEVERAGES-COFFEE & -2.320 & OIL/VINEGAR/COOKING WINE & 0.593 \\
\hline PREPARED FOOD & -2.260 & BEVERAGES-WATER & 0.606 \\
\hline BEVERAGES-JUICE/DRNKS & -2.244 & SOUP & 0.704 \\
\hline FRUIT SNACKS & -2.220 & ALL OTHER DAIRY & 0.732 \\
\hline GRAVY/MARINADE/SAUCES & -2.140 & BAGS/WRAPS/DISP CONTNRS & 0.758 \\
\hline SAUCES (RFG) & -2.049 & PET CARE & 0.780 \\
\hline FROZEN DINNERS/ENTREES & -1.926 & HAIR CARE & 0.815 \\
\hline SOUR CREAM & -1.880 & PRODUCE-VEGETABLES & 0.939 \\
\hline SEASONAL & -1.880 & MEAT-FRESH & 0.940 \\
\hline BREAKFAST (FROZEN) & -1.778 & YOGURT & 0.980 \\
\hline SALAD DRESSING/TOPPINGS & -1.732 & SEAFOOD-FRESH & 1.000 \\
\hline BEVERAGES-ISOTONICS & -1.560 & FAMILY PLANNING & 1.200 \\
\hline DELI-PACKAGED & -1.520 & PET CARE-CAT FOOD & 1.300 \\
\hline BUTTER/MARGARINE/SPREADS & -1.512 & INCONTINENCE & 1.370 \\
\hline SALTY SNACKS & -1.455 & SHAVING NEEDS & 1.407 \\
\hline BEER \& CIDER & -1.303 & PAPER & 1.740 \\
\hline DOUGH (RFG) & -1.259 & DISH CARE & 1.880 \\
\hline BREAD/DOUGH (FROZEN) & -1.222 & PET CARE-DOG FOOD & 1.976 \\
\hline ALL OTHER GENERAL MERC & -1.200 & DEODORANTS/ANTI-PERSP & 2.037 \\
\hline ICE CREAM TOPPINGS/CONES & -1.182 & EGGS/EGG SUBSTITUTES & 2.146 \\
\hline FRZN DESSERT/PIE/PASTRIES & -1.182 & EYE/EAR/FOOT CARE & 2.268 \\
\hline GELATN/PUDDNG SNCKS (RFG) & -1.152 & BEVERAGES-SOY/RICE & 2.296 \\
\hline NON-ALCOHOLIC BEER/WINE & -1.148 & LAUNDRY CARE & 2.512 \\
\hline OLIVE/PICKLE/PEPPERS (RFG) & -1.000 & HOUSEHOLD CLEANERS & 2.556 \\
\hline ENTERTAINMENT & -0.909 & MILK & 2.593 \\
\hline SPICES/EXTRACTS & -0.900 & FEMININE CARE & 2.700 \\
\hline BEVERAGES-HOT CHOCOLATE & -0.848 & VEGETABLES & 2.704 \\
\hline GELATIN/PUDDING & -0.788 & PRODUCE-FRUITS & 2.732 \\
\hline CRACKERS & -0.727 & VEGETABLES (FROZEN) & 2.829 \\
\hline PASTA (RFG) & -0.704 & VITAMINS & 2.852 \\
\hline SOFT GOODS & -0.606 & FIRST AID & 2.900 \\
\hline BEVERAGES (FROZEN) & -0.576 & ORAL HYGIENE & 3.390 \\
\hline FRUITS (FROZEN) & -0.545 & & \\
\hline
\end{tabular}

